\title{
Article \\ Comprehensive Investigations of Cutting with Round Insert: Introduction of a Predictive Force Model with Verification
}

\author{
Judit Lukács ${ }^{+}(\mathbb{D})$ and Richárd Horváth *,+(D)
}

check for updates

Citation: Lukács, J.; Horváth, R. Comprehensive Investigations of Cutting with Round Insert:

Introduction of a Predictive Force Model with Verification. Metals 2022, 12, 257. https://doi.org/10.3390/ met12020257

Academic Editor: Umberto Prisco

Received: 20 December 2021

Accepted: 24 January 2022

Published: 29 January 2022

Publisher's Note: MDPI stays neutral with regard to jurisdictional claims in published maps and institutional affiliations.

Copyright: (c) 2022 by the authors. Licensee MDPI, Basel, Switzerland. This article is an open access article distributed under the terms and conditions of the Creative Commons Attribution (CC BY) license (https:/ / creativecommons.org/licenses/by/ $4.0 /)$.
Bánki Donát Faculty of Mechanical and Safety Engineering, Óbuda University, H-1081 Budapest, Hungary; lukacs.judit@uni-obuda.hu

* Correspondence: horvath.richard@uni-obuda.hu

† These authors contributed equally to this work.

\begin{abstract}
The observation and prediction of cutting forces are key questions when planning manufacturing technologies. In this paper, all three force components are investigated in the case of turning with round insert. The specific cutting forces were used and adapted for the round insert. Two easily calculable parameters of the undeformed chip cross-section were introduced $\left(h_{e q}\right.$ - equivalent chip thickness and $l_{e f f}$-total length of the engaged cutting edge). The dependency of the specific force components was examined with regards to $h_{e q}$ and $l_{e f f}$. The main goal was to generate new empirical force models for each component, which helps to estimate their values in a wide range of technological parameters from fine to rough machining. The application of the models was confirmed by a case study where $11 \mathrm{SMn} 30+C(1.0715)$ was investigated. The examined interval of cutting parameters was: for feed, $f=0.12 \ldots 0.6 \mathrm{~mm}$, and for depth of cut, $a_{p}=1.2 \ldots 4.8 \mathrm{~mm}$. The novelty of the article is that the introduced new force models based on the geometric parameters characterizing the undeformed chip cross-section of round insert are proper for predicting the cutting force components in the technological process planning with an accuracy high enough-for main cutting force $\left(F_{c}\right)-3.79 \% \ldots+4.43 \%$, for feed force component $\left(F_{f}\right)-5.4 \% \ldots+5.99 \%$, and for radial force component $\left(F_{r}\right)-4.49 \%$.. $+4.77 \%$.
\end{abstract}

Keywords: cutting force mode; round insert; calculation of specific force components; total length of the engaged cutting edge; equivalent chip thickness

\section{Introduction}

The quality requirements of cut parts (e.g., geometrical accuracies, surface roughness parameters, etc.) are strongly influenced by the set cutting parameters, and also by the generated forces (see Figure 1).

Therefore, the investigation of cutting forces and the examination processes constitute an important field of research nowadays. In addition, the key question is to make the calculation methods more accurate. The cutting force and its spatial components are related to further important issues such as the geometric error of the finished workpiece, the energy consumption of the cutting operation, residual stress in the workpiece, adaptive control, and so forth. Carrino et al. [1] highlighted the need for the estimation of cutting force components in the case of turning. With the help of numerical examples, the connection between the workpiece diameter error and the cutting force components were demonstrated. Smith [2] revealed that the feed force component provides a better indication of the cutting edge's condition as a function of tool wear during a machining operation than the torque value. Although Gonzalo et al. [3] studied a clamping process, the main cause of part rejection was also stated: the static deformation and the dynamic vibrations. That is the static deformation, which is strongly affected by the process forces. The residual stress induced in turning was analyzed by Outeiro et al. [4] for workpiece material AISI 316L. It was revealed that the residual stress was sourced from several parts, such as the action of the cutting force components, the temperature generated, and the phase transformation in 
the surface layer. So, the knowledge and the investigation of the cutting forces and their components is an important research field in cutting technologies. The chronological order of some important cutting force models is shown in Figure 2.

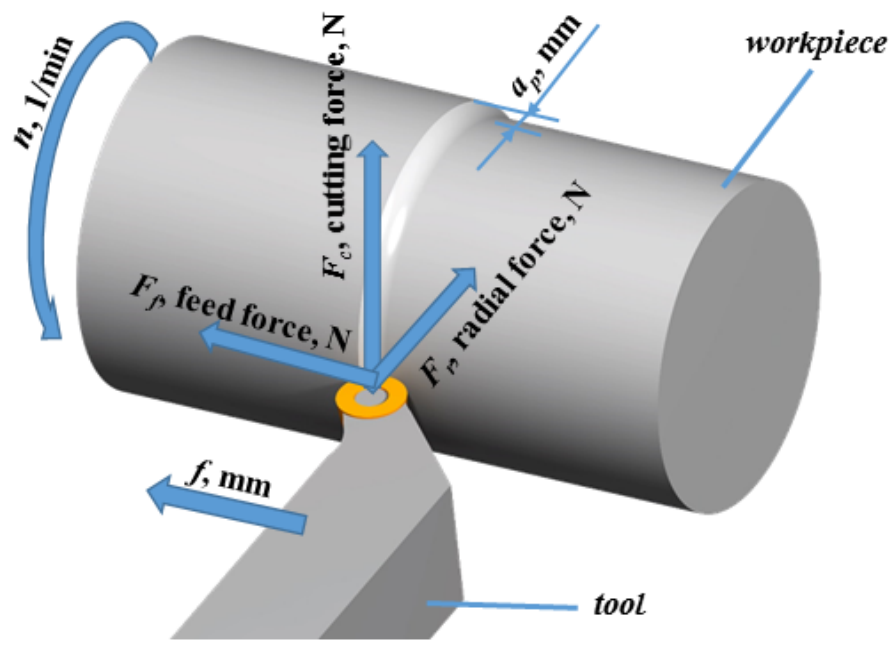

Figure 1. The force system of turning.

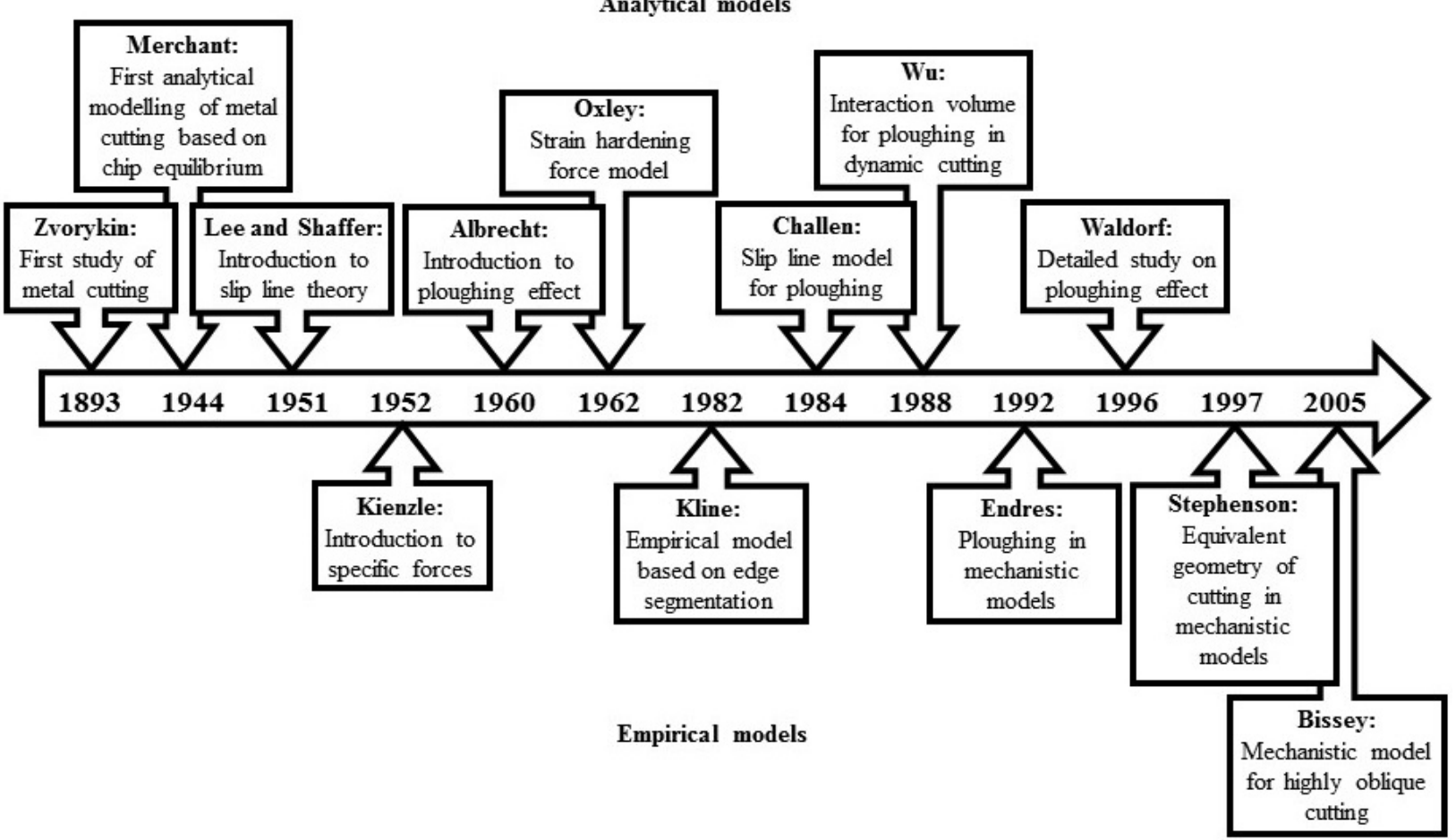

Figure 2. The history of cutting force models adapted from [5].

One of the most widely used force models with reasonable accuracy that can be applied in industrial conditions was presented by Kienzle and Victor [6,7]. The application of specific cutting force components and their equation is still an integral part of the teaching materials in theoretical cutting (books, textbooks, etc.) all over the world [2,8-12]. In the cutting force model of Kienzle and Victor, specific cutting forces $k_{i}$ were introduced and calculated with the help of empirically determined parameters $\left(k_{1.1}\right.$, and $\left.m\right)$. The force is called specific, as it consists of the cutting force divided by the chip cross-section linked to chip width $-b$ and thickness $-h$ (see Figure 3 ). 


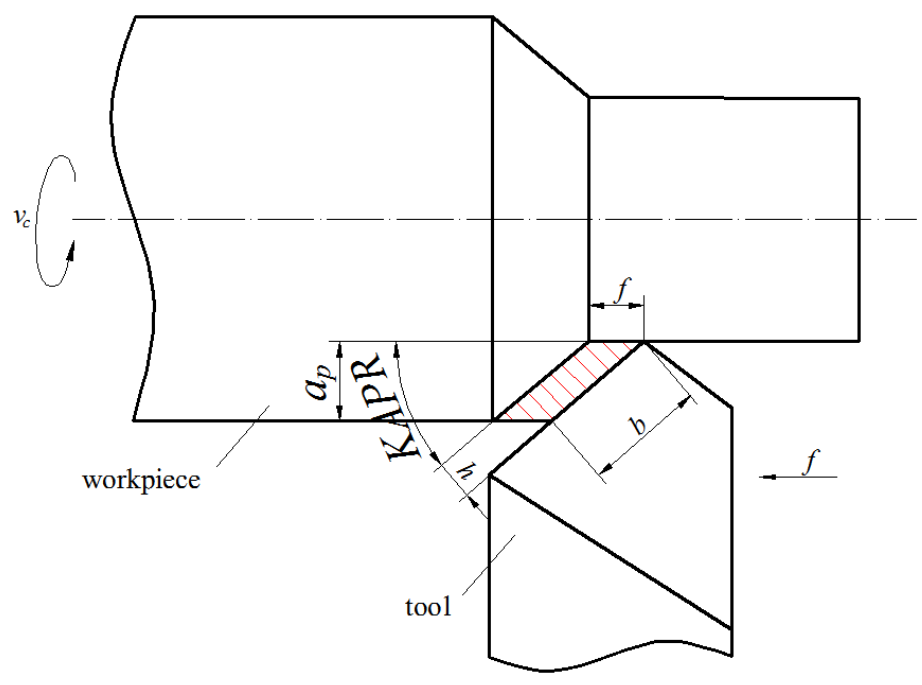

Figure 3. The theoretic chip cross-section in case of conventional roughing turning.

It means that, according to Kienzle, the main cutting force $\left(F_{c}\right)$ is equal to the product of the chip cross-section and specific cutting resistance of the workpiece material (see Equation (1)).

$$
F_{c}=A \cdot k_{c}
$$

To calculate the cutting force for many machining technologies, $F_{c}$ is determined by this approach. In the case of this method, chip geometry is important. The key factor, which determines the chip cross-section is a cutting edge angle (KAPR). Figure 3 shows the relationship between the cutting and the geometric parameters. Since

$$
\sin (K A P R)=\frac{h}{f}=\frac{a_{p}}{b}
$$

chip thickness and width can be determined according to Equations (2) and (3).

$$
\begin{gathered}
h=f \cdot \sin (K A P R) \\
b=\frac{a_{p}}{\sin (K A P R)} .
\end{gathered}
$$

The area of the undeformed chip cross-section can be calculated with the help of the set cutting parameters $\left(a_{p}, f\right)$ and by the geometric ones $(h, b)$ as well (see Equation (4)).

$$
A=a_{p} \cdot f=b \cdot h
$$

The formula for the specific cutting force in the direction of the main cutting force $\left(F_{c}\right)$ was presented by Equation (5),

$$
k=\frac{k_{1.1}}{h^{m}}
$$

where $k_{1.1}$ is the main value of the specific cutting force (in case of a chip cross-section where $h=1 \mathrm{~mm}$ and $b=1 \mathrm{~mm}) ; m$ is a constant value which is the characteristic slope of the curve showing relation between $k$ and $h$ values on a logarithmic scaled diagram. Both parameters are depending on the type of the material examined.

Nowadays, the precision, the refinement, and the adaptation of the Kienzle formula (Equation (5)), the application of the geometric parameters characterizing the chip crosssection $(h, b)$ are still important fields of research of cutting studies.

Cutting forces are strongly influenced by the set cutting parameters and by the tool geometry that should be involved in the models as correction factors. Korkut and Boy [13] investigated the effect of cutting parameters $\left(v_{c}, f, a_{p}\right)$ on the generated forces. Günay et al. [14] 
examined the influence of rake angle and cutting speed. Similar studies were carried out by Saglam et al. [15]; however, their experiments were expanded with the investigation of entering angle. It was revealed that with the increased positive rake angle, the cutting forces were decreased, which means less power demand. Since the cutting edge enters and leaves the workpiece gradually, the impact of the load is not exerted on it. The optimum entering angle was determined. In addition, it was demonstrated that the greater value of entering angle produces greater feed force but less thrust force.

Several studies deal with the investigations of specific cutting forces. Velchev et al. [16] tested the influence of cutting speed. It was concluded that the presented mathematical formulae can be used for the approximation of the dependency of the specific cutting force on the cutting speed in case of turning in a wide range. Fernández-Abia [17] studied the behavior of austenitic stainless steels at high speed turning using specific force coefficients. A mechanistic model was introduced for cutting force prediction.

In the case of hard turning (workpiece material: AISID3, hardness: 60HRC), Aouici et al. [18] examined the effect of cutting parameters $\left(v_{c}, f, a_{p}\right)$ on the cut surface roughness, cutting force, specific cutting force, and power.

Cobalt chromium alloys are materials for orthopedic implants mainly due to its unique properties of biocompatibility and wear resistance. Ahearne and Baron [19] reported initial research on cutting biomedical grade cobalt chrome molybdenum (Co-Cr-Mo) alloy, ASTM F75. Based on their results, the determination of the cutting force coefficients, as well as constants of the Kienzle equations, was enabled.

Specific cutting forces are strongly influenced by the chip geometry (Figure 3). Bíró and Szalay [20] presented the effect of the alteration of the chip thickness. Four zones were demonstrated from macro geometry to hypothetical micro-chip thickness based on whose specific cutting forces are characterized in a wide range of $h$.

Nowadays, one of the main goals with regards to sustainable manufacturing is energy efficiency that is undoubtedly influenced by the generated forces. As a result, several researchers are dealing with this topic. In their studies, cutting force components were estimated with the help of the Kienzle formula. Guo et al. [21] proposed and validated an operation-mode-based approach to decrease the energy consumption of machine tools which incorporates material removal simulation in order to predict the energy demand of machining processes.

The aim of Tapoglou et al. [22] was to construct an architecture for on-board online optimization of the cutting conditions. The main goals were to minimize both cutting time and power consumption at the same time.

The Kienzle equation or its elements are still used and adapted for the process planning procedure of several types of cutting technologies. Gonçalves and Schroeter [23] presented geometric modeling and simulation of helical broach using the equations that characterized the geometry. Traction force and torque acting on the broach shank were calculated by the Kienzle formula. Experiments were carried out with low speed using the longitudinal movement of a CNC lathe to determine the constants of the equation.

A commonly used method to manufacture high precision involute gears is gear hobbing. The cost-efficiency of the manufacturing process and the quality of the produced gear is strongly influenced by the generated forces and the wear of the cutting tool. Tapoglou et al. $[24,25]$ created a novel simulation code that was able to determine the time course of the cutting force components based on the Kienzle equation. With the help of the method presented, the complex movement of gear hobbing was involved, the total cutting forces, as well as the cutting forces in every cutting edge involved in the cutting process, were calculated.

The gear skiving technology is similar to gear hobbing. CAD simulation approach of gear skiving was presented by Antoniadis et al. [26,27]. In their papers, the cutting force components were calculated through the integration of elementary force components by the Kienzle formula. The coefficients of the Kienzle equation were analytically, experimentally determined for the specific tool-workpiece material combination. A similar issue is the 
drilling thrust force calculation that requires a large amount of experimental work. Kyratsis et al. $[28,29]$ showed an extensively validated CAD-based approach in their studies.

A 3-Dimensional kinematics simulation of face milling was showed by Tapoglou and Antoniadis [30] in which the cutting forces were calculated according to the Kienzle equation. The effect of cutting geometry on the surface roughness was examined as well.

Furthermore, the specific cutting force plays an important role in the micro-cutting process too. As the specific cutting force is a sensitive parameter, it must be better explored to evaluate the micro-machining processes. Oliviera et al. [31] compared the size effect behavior in micro- and macro-milling regarding the specific cutting force and investigated the effect of the tool edge radius, workpiece roughness, cutting force, and chip formation when milling slots of AISI 104 steel. Zhang et al. [32] established a milling force model for micro-end milling, which was based on the size effect of specific cutting force and validated by a series of experiments. The workpiece material was AISI 1045. It was stated that the specific cutting force of micro-milling increases with the decrease of feed per tooth and axial depth of cut. The helical angle of the tool has a strong effect on the specific cutting force; on the other hand, the cutting tool diameter has a minor effect. The specific cutting force in down-milling is larger than that in up-milling due to the impact of the cutting tool on the workpiece. Anand et al. [33] presented investigations of the size effects on cutting forces in micro-drilling of carbon fiber reinforced plastic composite (CFRP). Specific cutting forces were calculated by dividing cutting force components by chip cross-section. In the mathematical formula presented, the specific cutting force was determined as a function of the ratio of undeformed chip thickness to cutting edge radius. Regression analysis was carried out on the experimental results in order to count the coefficients. Thus, they successfully extended the Kienzle model for both specific thrust and radial forces in the micro-drilling of CFRP.

In the case of turning technologies, the knowledge and the estimation of cutting forces is a key question. Maier and Zaeh [34] showed an approach for the holistic modeling of process effects. In their studies, process heat, cutting forces, and increased load on feed and main drives were involved. The modeling of thermal boundary conditions required static mean values for the cutting process forces that were calculated by the Kienzle equation. Ntziantzias et al. [35] studied a new material-glass fiber reinforced polyamide-and experimentally determined the coefficients of the Kienzle formula for turning under dry conditions.

High productivity and geometrical flexibility, safe chip breaking, and machining of twist-free surfaces are proposed by the turn-milling technology. However, one of the main disturbances is the dynamic profile of precess forces. Hertel et al. [36] presented a new process model of orthogonal eccentric turn-milling. Their analysis was concentrated on the process forces and their dynamic behavior. The Kienzle force model was involved in the calculation of specific process forces to show their dependency on the chip thickness.

An analytical force prediction model for the turning process is shown by Weng et al. [37] and Zhuang et al. [38]. The model was based on the discretization of cutting edge and detailed geometric analysis with the consideration of edge effect and size effect and applied to the force distribution of round insert. Their method is developed to divide the uncut chip area of the round insert into many increments, and the local parameters of each increment can be calculated by the classical oblique cutting theory. Finally, cutting experiments were performed on Inconel 718 and Ti6Al4V to verify their model.

Horváth [39] introduced a new model for fine turning forces in which an exact description of cutting on the tool nose radius was presented as a function of the set cutting parameters. With the help of the generated model, cutting force components can be estimated easily with high accuracy in the case of fine turning. For the experimental runs, a new dynamometer system was developed as well [40] that was able to measure cutting forces of low values $(0 \ldots 100 \mathrm{~N})$. Horváth and Lukács [41] verified the applicability of the above-mentioned force model adapted for fine turning [39] for several types of materials 
(C45 and KO36 steel types, AS12 die-cast aluminium alloy). Ribeiro Filho et al. [42] adapted the method for turning force prediction of various titanium alloys.

In the past few years, tools with round inserts are widely used in industrial technologies; it has become an important field of research. Pradeep et al. [43] dealt with the modelling of cutting forces in face-milling operation using self-propelling round insert. Even in face-milling technology the proper estimation and analysis of the cutting force plays an important role in the process optimization. To solve this problem Ghorbani and Moetakef-Imani [44] presented a new method to identify the coefficients of the specific cutting force in the case of full immersion face-milling with round insert. An analytical model was introduced by Weng et al. [45] for cutting force prediction based on the precise cutting geometry. Cutting edge discretization was applied in high speed turning operations. Physical and technological points of view were chosen by P. Nieslony et al. [46]. Coated carbide round inserts were used in turning with Self-Propelled Rotary Tool. Feed, depth of cut and cutting speed values were varied to study the changes in cutting forces as a function of the cutting length. A special field of application is turning and re-turning of the rim profile of railway wheels (see Figure 4). In addition, new wheels are either turned with that tool type or face milled. Since, in contrast to conventional tools (see Figure 3), a round insert does not have classic, straight-line-bounded geometry and definable main cutting angle, the wide range of application justifies the need for the adaptation of a new force model for the particular characteristics of the chip cross-section in these cases. In this paper, the new force model is adapted for turning with round insert. Furthermore, with the help of the new equations, the components of the generated spatial force system can be precisely calculated and studied in detail.

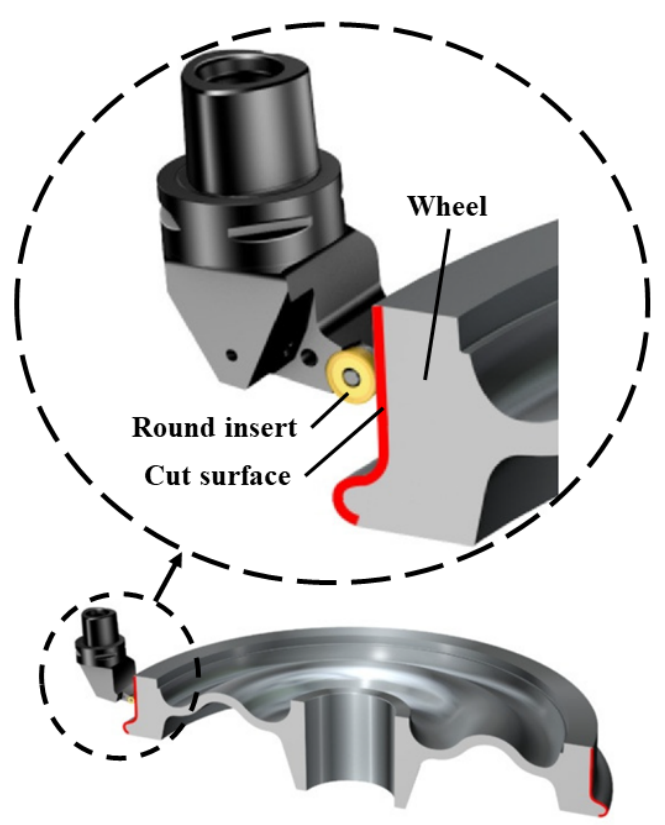

Figure 4. Roughing operation of the rim profile of railway wheel (adpated from [47]).

\section{Materials and Methods}

\subsection{Materials and Tool Used}

The cutting tests were carried out on 11SMn30+C (1.0715) steel. The overall size of the workpiece was $\varnothing 100 \times 150 \mathrm{~mm}$. The chemical composition is (in wt \%): $\mathrm{C}=0.08 ; \mathrm{Si}<0.05$; $\mathrm{Mn}=1.1 ; \mathrm{P}=0.07 ; \mathrm{S}=0.3$. (Hardness: $112 \ldots 169 \mathrm{HB}$ ). Turning studies were implemented with round insert coded RCMT 1204 M0 $4325(R E=12 \mathrm{~mm})$ and the tool holder was SRSCR 2525M 12 (Sandvik Coromant). 


\subsection{Machine and Device Used}

The experiments were performed with Dugard Eagle BNC-1840 CNC lathe. (The main technical parameters are as follows: spindle speed is $100 \ldots 45001 / \mathrm{min}$, and the machine performance is $7.58 \mathrm{~kW}$ ). A KISTLER $9257 \mathrm{~b}$ type dynamometer was used for the force measurements, the measurement range of which was: $F_{c}=-5 \ldots 10 \mathrm{kN}$ and $F_{f}, F_{r}=-5 \ldots 5 \mathrm{kN}$. The dynamometer was linked to the KISTLER 5019 type charge amplifier. The evaluation of the cutting force components was processed with DynoWare software.

\subsection{Adaptation of the Force Model for Round Insert}

In the case of turning with round insert, the chip removal takes place on an arc (radius of the insert $\sim$ tool nose radius). Based on the value of the depth of cut, two types of undeformed chip cross-section can occur: $a_{p}<\mathrm{RE}$ and $a_{p}>\mathrm{RE}$ (see Figure 5). Note that the case of $a_{p}>$ RE was examined from a theoretical point of view; to compare to the first case in a mathematical sense when determining $l_{e f f}$. It can be stated that both of them significantly differ from the one defined by Kienzle (see Figure 3).

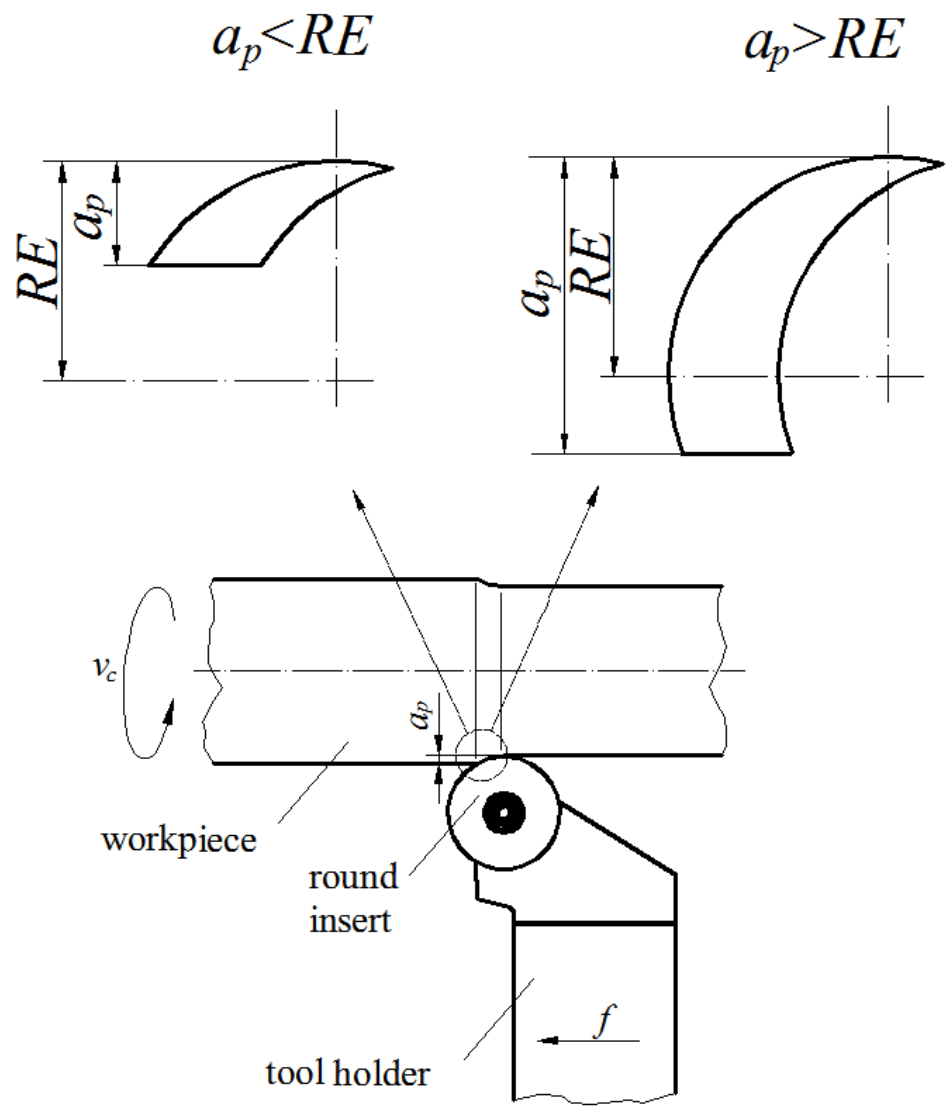

Figure 5. The shapes of undeformed cross-section on the round tool.

As a result, novel parameters characterizing the undeformed chip cross-section are needed [48]. In addition, it is advisable to substitute the chip cross-sections shown in Figure 5 with an equivalent one, the area of which equals the real, undeformed chip crosssection. Thus, $h_{e q}, \mathrm{~mm}$ equivalent chip thickness, and $l_{e f f}, \mathrm{~mm}$ effective cutting length, the total length of the engaged cutting edge (see Figure 6) were introduced. 


$$
A_{\text {undeformed }}^{\text {chip cross-section }}=A_{\text {equivalent theoretic }}
$$

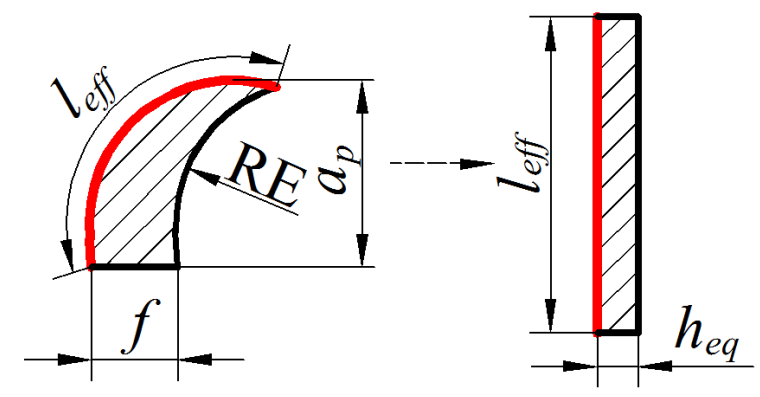

Figure 6. The connection between the undeformed cross-section and equivalent one.

The effective cutting length is calculated in two parts, the first of which is behind the contact point of the tool and the workpiece (opposite direction of feed) $-l_{\text {eff } 1 \text {-and the other }}$ one is in the feed direction- $l_{e f f 2}$ (see Equation (6)).

$$
l_{\text {eff }}=l_{\text {eff } 1}+l_{\text {eff } 2} .
$$

According to Figure 7 , the first component, $l_{e f f 1}$ is only the function of the feed and the insert radius. In order to calculate its value, the arc length belonging to $\varphi_{1}$ has to be expressed as follows: The circumference of the mentioned sector of the circle is counted as the multiplication of the insert radius and the angle $\varphi_{1}$ (Equation (7)).

$$
l_{e f f 1}=f(R E ; f)=R E \cdot \varphi_{1} .
$$

Based on Figure 7 and on the sine trigonometric function, angle $\varphi_{1}$ can be calculated according to Equation (8).

$$
\sin \varphi_{1}=\frac{f}{2 \cdot R E} \Rightarrow \varphi_{1}=\arcsin \frac{f}{2 \cdot R E} .
$$

The first part of the total length of engaged cutting edge, shown in Equation (6), can be expressed by integrating Equations (7) and (8).

$$
l_{e f f 1}=R E \cdot \varphi_{1}=R E \cdot\left[\arcsin \frac{f}{2 \cdot R E}\right] .
$$

The length of the second component $\left(l_{e f f 2}\right)$ only depends on the depth of cut and the insert radius (see Figures 8 and 9). Similarly to the first part, the length of the arc is calculated with the help of the insert radius and the angle belonging to the set value of the depth of cut (Equation (10)).

$$
l_{e f f 2}=f\left(R E ; a_{p}\right)=R E \cdot \varphi_{2} .
$$

However, in this case, two different situations occur based on the values of $a_{p}$. Firstly, when $a_{p}>R E$, the sine function is applied on the side angle $\left(\varphi_{2 a}^{\prime}\right)$ of the supplementary triangle shown in Figure 8). 


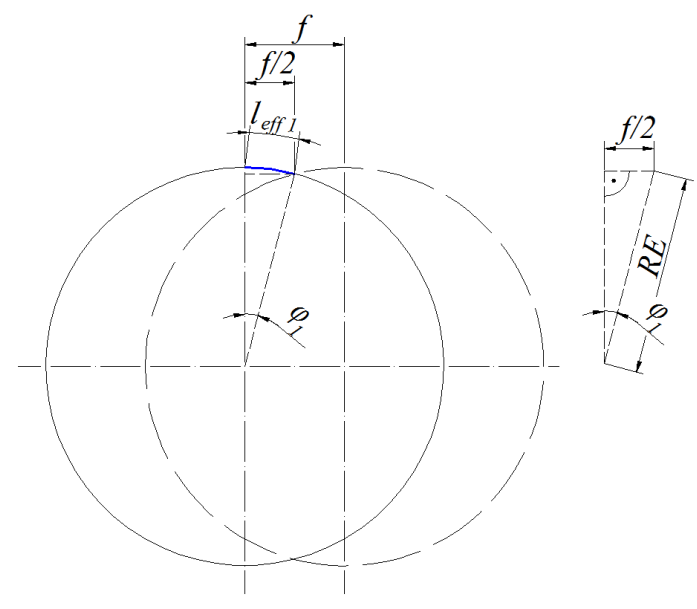

Figure 7. The define of $l_{\text {eff } 1}$.

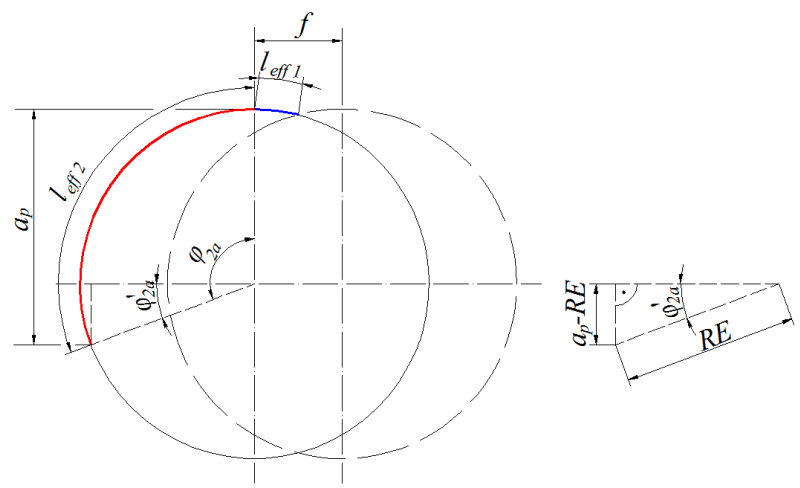

Figure 8. Define $l_{e f f 2}$ if $a_{p}$ is bigger than $R E$.

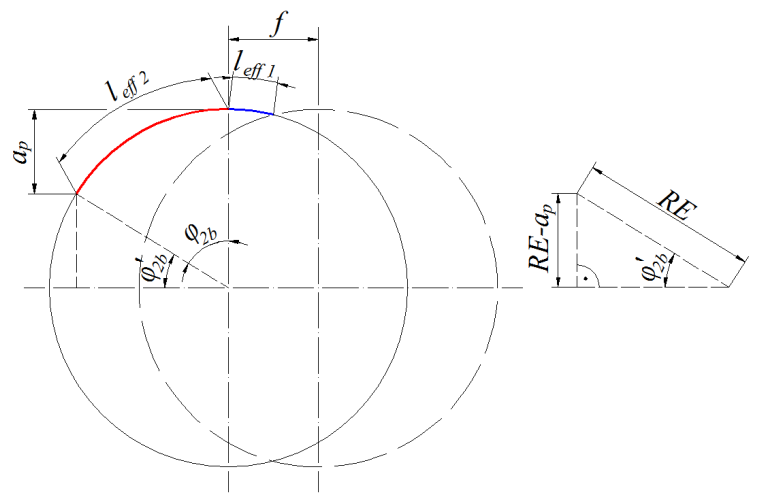

Figure 9. Define $l_{e f f 2}$ if $a_{p}$ is smaller than $R E$.

With the help of Equations (11) and (12) $\varphi_{2 a}$ is calculated according to Equation (13).

$$
\begin{gathered}
\varphi_{2 a}=\frac{\pi}{2}+\varphi_{2 a}^{\prime} \\
\sin \varphi_{2 a}^{\prime}=\frac{a_{p}-R E}{R E}=\frac{a_{p}}{R E}-1 \Rightarrow \varphi_{2 a}^{\prime}=\arcsin \left(\frac{a_{p}}{R E}-1\right) \\
\varphi_{2 a}=\frac{\pi}{2}+\varphi_{2 a}^{\prime}=\frac{\pi}{2}+\arcsin \left(\frac{a_{p}}{R E}-1\right) .
\end{gathered}
$$

Having put Equation (13) into (10), Equation (14) shows the formula for calculating the effective cutting length.

$$
l_{e f f 2 a}=R E \cdot \varphi_{2 a}=R E \cdot\left[\frac{\pi}{2}+\arcsin \left(\frac{a_{p}}{R E}-1\right)\right] .
$$


Figure 9 shows the second case when the $a_{p}<R E$ relation is satisfied.

The side angle of the supplementary triangle can be found on the outside of the angle belonging to the insert radius and the set cutting parameter $a_{p}$. It is calculated according to Equation (15).

$$
\varphi_{2 b}=\frac{\pi}{2}-\varphi_{2 b}^{\prime} .
$$

With the help of the sine function, $\varphi_{2 b}^{\prime}$ side angle is determined (Equation (16)).

$$
\sin \varphi_{2 b}^{\prime}=\frac{R E-a_{p}}{R E}=1-\frac{a_{p}}{R E} \Rightarrow \varphi_{2 b}^{\prime}=\arcsin \left(1-\frac{a_{p}}{R E}\right) .
$$

It can be stated that the side angle in both cases is similar (see Equations (12) and (16)).

$$
-\arcsin x=\arcsin (-x) .
$$

Since arcsine is an odd function (its nature is shown in Equation (17)), the conversion demonstrated in Equation (18) is valid. As a result, the formula of $\varphi_{2 b}$ can be transformed according to Equation (18)

$$
\varphi_{2 b}=\frac{\pi}{2}-\varphi_{2 b}^{\prime}=\frac{\pi}{2}-\arcsin \left(1-\frac{a_{p}}{R E}\right)=\frac{\pi}{2}+\arcsin \left(\frac{a_{p}}{R E}-1\right) .
$$

With the help of the above-mentioned connections, the second part of the effective cutting length can be calculated with the same formula in both cases (see Equation (19)).

$$
l_{e f f 2 b}=R E \cdot \varphi_{2 b}=R E \cdot\left[\frac{\pi}{2}+\arcsin \left(\frac{a_{p}}{R E}-1\right)\right]=l_{e f f 2 a}=l_{e f f 2} .
$$

The total length of the engaged cutting length is determined according to Equation (20) by combining Equations (6), (9) and (19).

$$
l_{e f f}=R E \cdot\left[\frac{\pi}{2}+\arcsin \left(\frac{a_{p}}{R E}-1\right)+\arcsin \frac{f}{2 \cdot R E}\right] .
$$

It can be seen that the effective, operational cutting length can be calculated from the set cutting parameters $\left(a_{p}\right.$ and $\left.R E\right)$. The other parameter, the equivalent chip thickness, can be determined with the help of Equation (21).

$$
A=a_{p} \cdot f=l_{e f f} \cdot h_{e q} \Rightarrow h_{e q}=\frac{A}{l_{e f f}}=\frac{a \cdot f}{l_{e f f}} .
$$

Based on the mechanical analogy, specific cutting force components can be determined by Equation (22) for all directions.

$$
k=\frac{F}{A}=\frac{F}{l_{e f f} \cdot h_{e q}} .
$$

Since the specific cutting force is strongly influenced by the geometric parameters of the undeformed chip cross-section $\left(l_{e f f}\right.$ and $\left.h_{e q}\right)$, the formerly determined (Equation (5)) was expanded (see Equation (23)),

$$
k=C \cdot h_{e q}{ }^{m} \cdot l_{e f f}{ }^{n},
$$

where $C$ is a constant value, $m$ is characterizing the connection between $k$ and $h_{e q}$ in a logarithmically scaled diagram (expected to have a negative value), and $n$ is the exponent of the total length of the engaged cutting edge. 
Finally, in Equation (24) the formula of the force model for turning with round insert is introduced.

$$
F=k \cdot A=\left(C \cdot h_{e q}^{m} \cdot l_{e f f}^{n}\right) \cdot\left(l_{e f f} \cdot h_{e q}\right)=C \cdot h_{e q}^{m+1} \cdot l_{e f f}^{n+1} .
$$

\section{Measurements}

The experimental setup (see Figure 10) was developed aiming to investigate possibly the widest technological range of turning with round insert. On the one hand, the suggestions of the manufacturer were taken into consideration when choosing the interval of the input variables. In addition, the required machining performance was observed as well. Due to the above-mentioned requirements, the value of the feed was set in four $(f=1.2 \ldots 4.8 \mathrm{~mm})$, the depth of cut in nine $\left(a_{p}=0.12 \ldots 0.6 \mathrm{~mm}\right)$ equidistant levels (see marked with blue on Figure 11). In addition, further confirmation measurement points were determined within the investigated interval of technological parameters (marked with red on Figure 11). Several studies have already dealt with the connection between the cutting speed and the force values $[13,15,16,18,49-54]$. Since either the less influential or a negligible effect was revealed, cutting speed was held on a constant value during the examinations: $v_{c}=150 \mathrm{~m} / \mathrm{min}$. In the case of each experimental run, the cutting length was chosen to have a machining time of $3 \ldots 5 \mathrm{~s}$ in order to be able to evaluate the cutting force components with higher accuracy. In the case of each experimental run, the cutting length was chosen to have a machining time of $3 . .5 \mathrm{~s}$ in order to be able to evaluate the cutting force components with higher accuracy.The cutting force components were registered at a sampling frequency of $500 \mathrm{~Hz}$ at each measurement point. After filtering the measurement results, the average cutting force values were evaluated at the experimental runs.

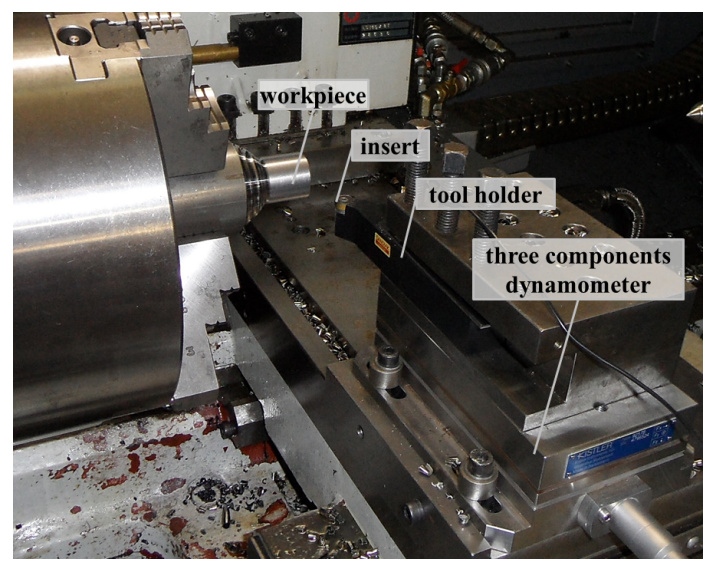

Figure 10. Experimental setup.

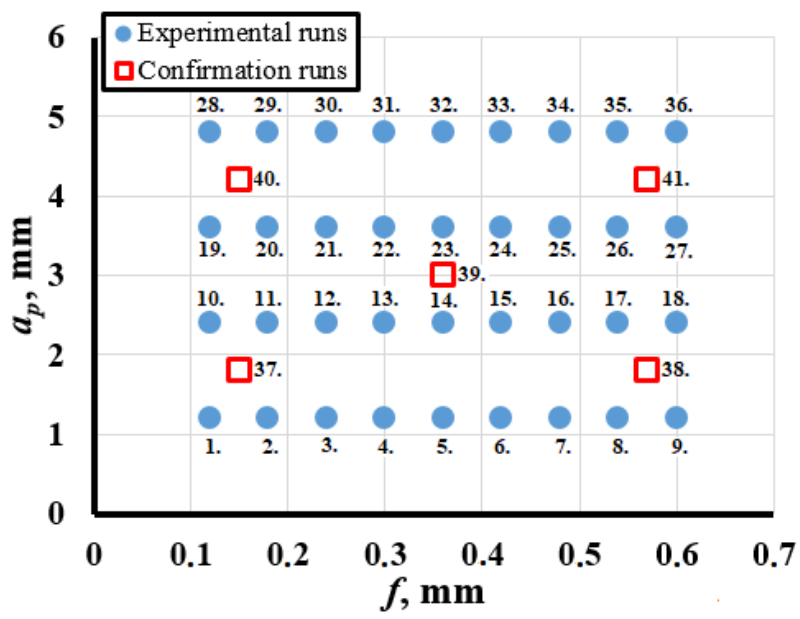

Figure 11. The location of the experimental and confirmation runs in the cutting parameter range. 


\section{Results}

In the case of turning with round insert, a significance test was carried out for each component in order to determine the influential parameters of the undeformed chip crosssection $\left(h_{e q}\right.$ and $\left.l_{e f f}\right)$. The results showed that $l_{e f f}$ has a non-significant effect on $k_{c}$ (in line with the Kienzle model [6,7], see Equation (5)). In addition, it can be seen in Figure 12a as well.

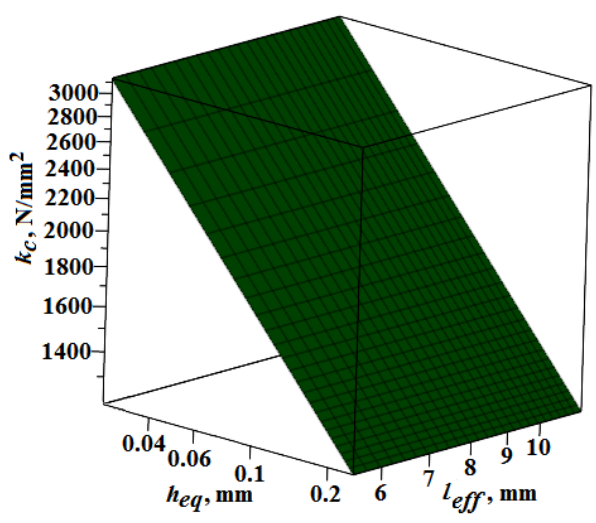

(a) 3D surface of $k_{c}$

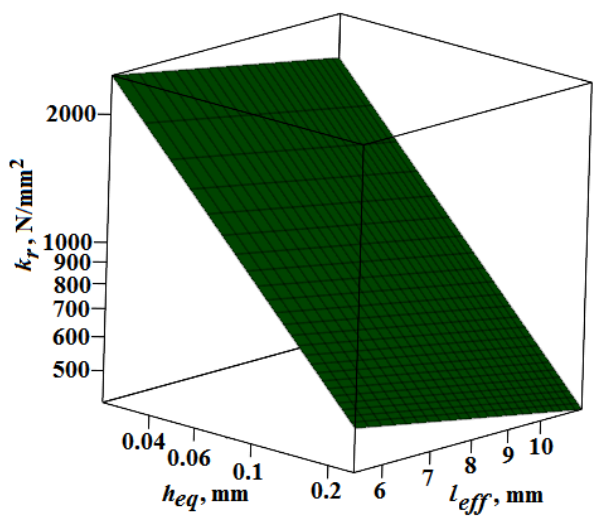

(c) 3D surface of $k_{r}$

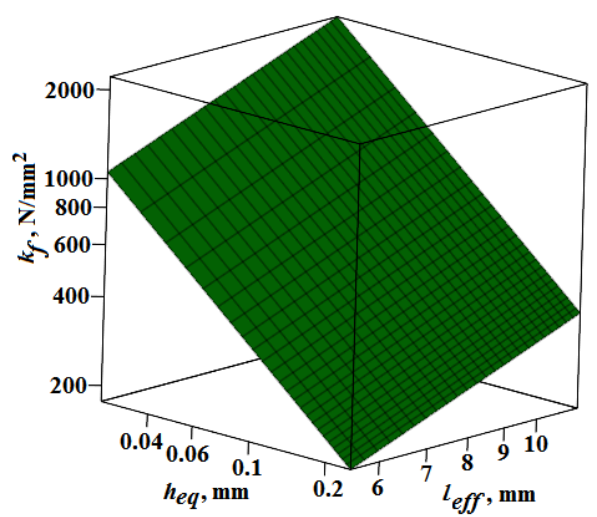

(b) 3D surface of $k_{f}$

Figure 12. Specific force components plotted against $l_{e f f}$ and $h_{e q}$.

Based on Figure 12, in the case of each component, the decreased value of $h_{e q}$ results in increased specific cutting force. Although, the higher value of $l_{\text {eff }}$ gives a higher $k_{f}$ (see Figure 12b). In contrast, the increased $k_{r}$ is resulted by the lower $l_{\text {eff }}$ (see Figure 12c).

As a result, nonlinear regression was fit on the measurement data, and the constants of Equation (23) were calculated. The formulae for the specific cutting force components are shown in Equations (25)-(27):

$$
\begin{gathered}
k_{c}=693 \cdot h_{e q}^{-0.409} \cdot l_{e f f}^{0} \\
k_{f}=10.8 \cdot h_{e q}{ }^{-0.790} \cdot l_{e f f}^{1.006} \\
k_{r}=367 \cdot h_{e q}-0.676 \cdot l_{e f f}^{-0.326} .
\end{gathered}
$$

The conformity of Equations (25)-(27) was examined on probability plots (see Figure 13). It can be stated that the relative residuals of the specific force components follow Gaussian distribution with low values of means. Thus, the introduced formulae are proper to study the generated spatial force system with adequate accuracy in the case of turning with round insert. 


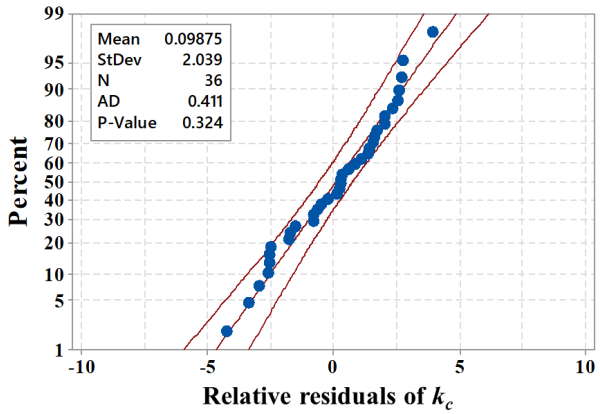

(a) Residuals of Equation (25)

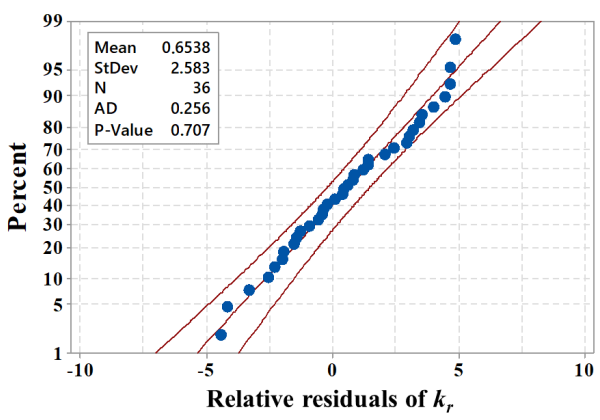

(c) Residuals of Equation (27)

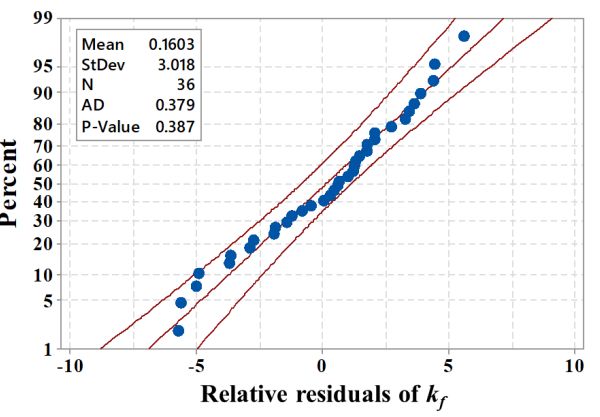

(b) Residuals of Equation (26)

Figure 13. The investigation of the residuals on probability plots.

Additionally, based on Equation (24) the force components can be calculated as follows:

$$
\begin{gathered}
F_{c}=693 \cdot h_{e q}^{0.591} \cdot l_{e f f}^{1} \\
F_{f}=10.8 \cdot h_{e q}^{0.210} \cdot l_{e f f} 2.006 \\
F_{r}=367 \cdot h_{e q}{ }^{0.324} \cdot l_{e f f}{ }^{0.674} .
\end{gathered}
$$

In Table 1, the experimental measurement data and the calculated ones (by Equations (28)-(30)) are involved. Furthermore, the percentage differences are shown as well.

Figure 14 shows the calculated cutting values as a function of measured ones for each component. The identity function $(x=y)$ would mean the perfect fit. It can be stated that Equations (28)-(30) give a good approximation for the cutting forces components. The deviations are as follows: for main cutting force $-F_{c}$ : $-3.79 \% \ldots+4.43 \%$, for feed force component $-F_{f}:-5.4 \% \ldots+5.99 \%$, and for radial force component $-F_{r}:-4.49 \% \ldots+4.77 \%$.

\section{The Model Confirmation}

The conformity of the model was proved in five measurement points. These further experimental runs were chosen from the range of the examined technological parameters; however, these significantly differed from the basic measurement points. In Figure 15 (37-41 confirmation runs), the measured and the calculated values of the force components are compared.

It can be stated that the accuracy is high enough; the highest deviations in the three directions are the following: in case of $F_{c}-1.44 \%-0.67 \%$, for $F_{f}-0.2 \%-3.58 \%$; and for $F_{r}$ $-1.03 \%-4.01 \%$. 
Table 1. The comparison of the measured and calculated force values.

\begin{tabular}{|c|c|c|c|c|c|c|c|c|c|c|c|c|c|c|}
\hline $\begin{array}{l}\text { Exp. } \\
\text { Runs }\end{array}$ & $\begin{array}{l}a_{p,} \\
\mathrm{~mm}\end{array}$ & $f, \mathrm{~mm}$ & $\begin{array}{l}l_{\text {eff }}, \\
\mathrm{mm}\end{array}$ & $\begin{array}{l}h_{e q}, \\
\mathrm{~mm}\end{array}$ & $\underset{\mathrm{mm}^{2}}{A,}$ & $\begin{array}{c}F_{c \_ \text {meas }}, \\
\mathbf{N}\end{array}$ & $\begin{array}{c}F_{c_{-} \text {calc }}, \\
\mathbf{N}\end{array}$ & $\Delta F_{c}, \%$ & $\underset{\mathbf{N}}{F_{f_{-m e a s}}}$ & $\underset{\mathbf{N}}{F_{f_{\text {calc }}}}$ & $\Delta F_{f}, \%$ & $\begin{array}{c}F_{r_{-} \text {meas }} \\
\mathbf{N}\end{array}$ & $\begin{array}{l}F_{r_{-} \text {calc }}, \\
\mathbf{N}\end{array}$ & $\Delta F_{r}, \%$ \\
\hline 1 & 1.2 & 0.12 & 5.4723 & 0.0263 & 0.144 & 444 & 443 & -0.13 & 150 & 152 & 1.33 & 340 & 355 & 4.41 \\
\hline 2 & 1.2 & 0.18 & 5.5023 & 0.0393 & 0.216 & 571 & 565 & -1.13 & 173 & 167 & -3.47 & 414 & 405 & -2.17 \\
\hline 3 & 1.2 & 0.24 & 5.5323 & 0.0521 & 0.288 & 675 & 670 & -0.67 & 188 & 179 & -4.79 & 458 & 446 & -2.62 \\
\hline 4 & 1.2 & 0.3 & 5.5623 & 0.0647 & 0.360 & 734 & 766 & 4.43 & 181 & 189 & 4.42 & 474 & 480 & 1.27 \\
\hline 5 & 1.2 & 0.36 & 5.5923 & 0.0772 & 0.432 & 826 & 855 & 3.56 & 190 & 199 & 4.74 & 509 & 510 & 0.20 \\
\hline 6 & 1.2 & 0.42 & 5.6223 & 0.0896 & 0.504 & 914 & 939 & 2.73 & 203 & 207 & 1.97 & 545 & 538 & -1.28 \\
\hline 7 & 1.2 & 0.48 & 5.6523 & 0.1019 & 0.576 & 999 & 1018 & 1.91 & 212 & 215 & 1.42 & 571 & 562 & -1.58 \\
\hline 8 & 1.2 & 0.54 & 5.6823 & 0.1140 & 0.648 & 1065 & 1094 & 2.70 & 214 & 223 & 4.21 & 588 & 585 & -0.51 \\
\hline 9 & 1.2 & 0.6 & 5.7124 & 0.1260 & 0.720 & 1135 & 1166 & 2.77 & 217 & 230 & 5.99 & 600 & 607 & 1.17 \\
\hline 10 & 2.4 & 0.12 & 7.7820 & 0.0370 & 0.288 & 782 & 771 & -1.39 & 332 & 330 & -0.60 & 525 & 502 & -4.38 \\
\hline 11 & 2.4 & 0.18 & 7.8120 & 0.0553 & 0.432 & 977 & 981 & 0.42 & 369 & 362 & -1.90 & 601 & 574 & -4.49 \\
\hline 12 & 2.4 & 0.24 & 7.8420 & 0.0735 & 0.576 & 1153 & 1164 & 0.99 & 398 & 387 & -2.76 & 653 & 631 & -3.37 \\
\hline 13 & 2.4 & 0.3 & 7.8720 & 0.0915 & 0.720 & 1290 & 1330 & 3.13 & 407 & 409 & 0.49 & 686 & 679 & -1.02 \\
\hline 14 & 2.4 & 0.36 & 7.9020 & 0.1093 & 0.864 & 1445 & 1484 & 2.68 & 425 & 428 & 0.71 & 726 & 721 & -0.69 \\
\hline 15 & 2.4 & 0.42 & 7.9320 & 0.1271 & 1.008 & 1597 & 1628 & 1.91 & 439 & 445 & 1.37 & 763 & 759 & -0.52 \\
\hline 16 & 2.4 & 0.48 & 7.9620 & 0.1447 & 1.152 & 1765 & 1764 & -0.08 & 451 & 460 & 2.00 & 791 & 794 & 0.38 \\
\hline 17 & 2.4 & 0.54 & 7.9920 & 0.1622 & 1.296 & 1912 & 1893 & -0.97 & 459 & 475 & 3.49 & 820 & 826 & 0.73 \\
\hline 18 & 2.4 & 0.6 & 8.0220 & 0.1795 & 1.440 & 2050 & 2018 & -1.56 & 473 & 489 & 3.38 & 849 & 855 & 0.71 \\
\hline 19 & 3.6 & 0.12 & 9.6048 & 0.0450 & 0.432 & 1081 & 1068 & -1.22 & 522 & 525 & 0.57 & 632 & 617 & -2.37 \\
\hline 20 & 3.6 & 0.18 & 9.6348 & 0.0673 & 0.648 & 1349 & 1358 & 0.68 & 583 & 575 & -1.37 & 716 & 704 & -1.68 \\
\hline 21 & 3.6 & 0.24 & 9.6648 & 0.0894 & 0.864 & 1596 & 1611 & 0.97 & 626 & 614 & -1.92 & 774 & 774 & 0.00 \\
\hline 22 & 3.6 & 0.3 & 9.6948 & 0.1114 & 1.080 & 1810 & 1840 & 1.68 & 639 & 647 & 1.25 & 808 & 833 & 3.09 \\
\hline 23 & 3.6 & 0.36 & 9.7248 & 0.1333 & 1.296 & 2036 & 2052 & 0.79 & 664 & 676 & 1.81 & 855 & 884 & 3.39 \\
\hline 24 & 3.6 & 0.42 & 9.7548 & 0.1550 & 1.512 & 2260 & 2250 & -0.43 & 683 & 702 & 2.78 & 896 & 931 & 3.91 \\
\hline 25 & 3.6 & 0.48 & 9.7848 & 0.1766 & 1.728 & 2534 & 2438 & -3.79 & 735 & 726 & -1.22 & 968 & 973 & 0.52 \\
\hline 26 & 3.6 & 0.54 & 9.8148 & 0.1981 & 1.944 & 2685 & 2617 & -2.55 & 770 & 748 & -2.86 & 1015 & 1012 & -0.30 \\
\hline 27 & 3.6 & 0.6 & 9.8448 & 0.2194 & 2.160 & 2842 & 2788 & -1.90 & 807 & 769 & -4.71 & 1070 & 1048 & -2.06 \\
\hline 28 & 4.8 & 0.12 & 11.1875 & 0.0515 & 0.576 & 1366 & 1347 & -1.39 & 726 & 733 & 0.96 & 698 & 714 & 2.29 \\
\hline 29 & 4.8 & 0.18 & 11.2175 & 0.0770 & 0.864 & 1712 & 1713 & 0.05 & 800 & 802 & 0.25 & 792 & 815 & 2.90 \\
\hline 30 & 4.8 & 0.24 & 11.2475 & 0.1024 & 1.152 & 2034 & 2032 & -0.10 & 856 & 856 & 0.00 & 871 & 896 & 2.87 \\
\hline 31 & 4.8 & 0.3 & 11.2775 & 0.1277 & 1.440 & 2323 & 2320 & -0.11 & 869 & 902 & 3.80 & 922 & 964 & 4.56 \\
\hline 32 & 4.8 & 0.36 & 11.3075 & 0.1528 & 1.728 & 2656 & 2587 & -2.60 & 925 & 941 & 1.73 & 979 & 1023 & 4.49 \\
\hline 33 & 4.8 & 0.42 & 11.3376 & 0.1778 & 2.016 & 2891 & 2836 & -1.90 & 985 & 977 & -0.81 & 1028 & 1077 & 4.77 \\
\hline 34 & 4.8 & 0.48 & 11.3676 & 0.2027 & 2.304 & 3149 & 3072 & -2.45 & 1047 & 1009 & -3.63 & 1089 & 1125 & 3.31 \\
\hline 35 & 4.8 & 0.54 & 11.3976 & 0.2274 & 2.592 & 3378 & 3297 & -2.41 & 1098 & 1040 & -5.28 & 1155 & 1170 & 1.30 \\
\hline 36 & 4.8 & 0.6 & 11.4276 & 0.2520 & 2.880 & 3591 & 3512 & -2.20 & 1129 & 1068 & -5.40 & 1189 & 1212 & 1.93 \\
\hline $\begin{array}{l}\text { Conf. } \\
\text { Runs }\end{array}$ & $\begin{array}{c}a_{p}, \\
\mathbf{m m}\end{array}$ & $f, \mathrm{~mm}$ & $\begin{array}{l}l_{\text {eff }}, \\
\mathbf{m m}\end{array}$ & $\begin{array}{l}h_{e q}, \\
\mathrm{~mm}\end{array}$ & $\begin{array}{c}A, \\
\text { mm }^{2}\end{array}$ & $\underset{\mathbf{N}}{F_{c \_ \text {meas }},}$ & $\underset{\mathbf{N}}{F_{c \_c a l c}}$ & $\Delta F_{c}, \%$ & $\begin{array}{c}F_{f_{-} \text {meas }} \\
\mathbf{N}\end{array}$ & $\frac{F_{f_{-c a l c}}}{\mathbf{N}}$ & $\Delta F_{f}, \%$ & $\begin{array}{c}F_{r_{-} \text {meas }} \\
\mathbf{N}\end{array}$ & $\begin{array}{c}F_{r_{-} \text {calc }} \\
\mathbf{N}\end{array}$ & $\Delta F_{r}, \%$ \\
\hline 37 & 1.8 & 0.15 & 0.0401 & 6.7327 & 0.270 & 695 & 697 & 0.33 & 243 & 252 & 3.58 & 479 & 474 & -1.03 \\
\hline 38 & 4.2 & 0.15 & 0.0604 & 10.4335 & 0.630 & 1367 & 1376 & 0.67 & 654 & 661 & 1.10 & 718 & 726 & 1.11 \\
\hline 39 & 3 & 0.36 & 0.1220 & 8.8528 & 1.028 & 1795 & 1769 & -1.44 & 547 & 551 & 0.78 & 810 & 814 & 0.49 \\
\hline 40 & 1.8 & 0.57 & 0.1478 & 6.9428 & 1.026 & 1546 & 1554 & 0.53 & 341 & 352 & 3.26 & 736 & 735 & -0.17 \\
\hline 41 & 4.2 & 0.57 & 0.2249 & 10.6436 & 2.394 & 3093 & 3054 & -1.28 & 909 & 907 & -0.20 & 1076 & 1121 & 4.01 \\
\hline
\end{tabular}

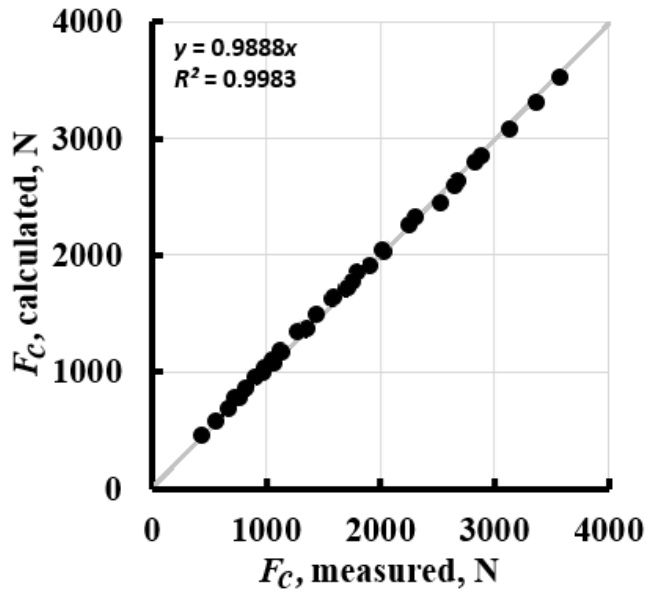

(a) Main cutting force $\left(F_{c}\right)$

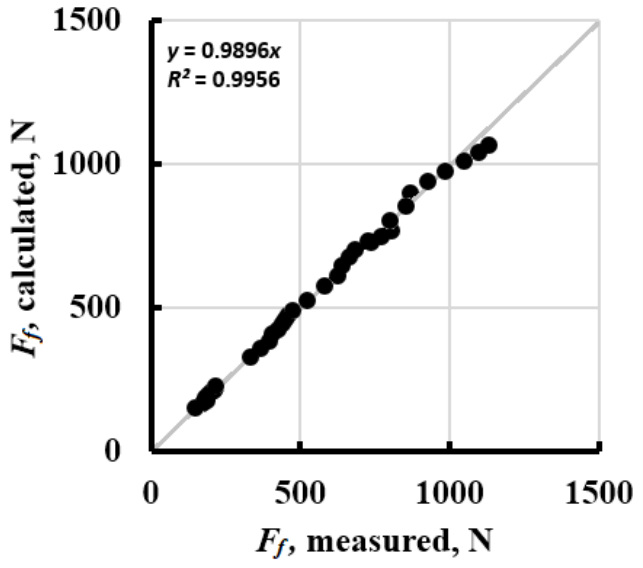

(b) Feed force $\left(F_{f}\right)$

Figure 14. Cont. 


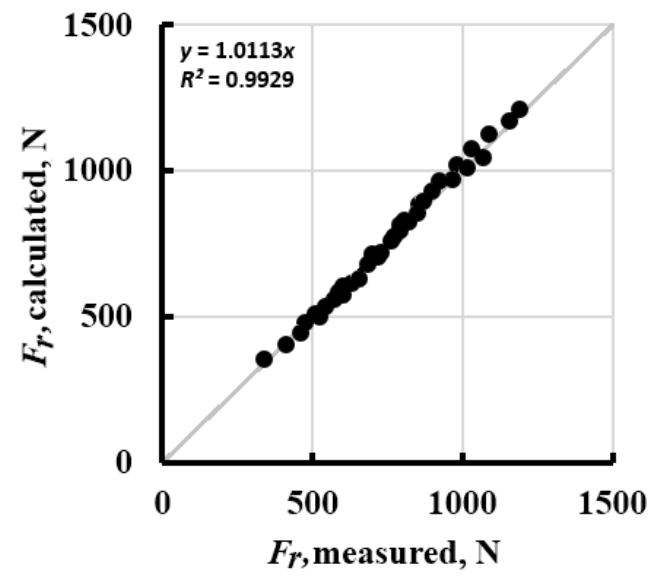

(c) Radial force $\left(F_{r}\right)$

Figure 14. The graphic comparison of the measured and calculated values of the force components.

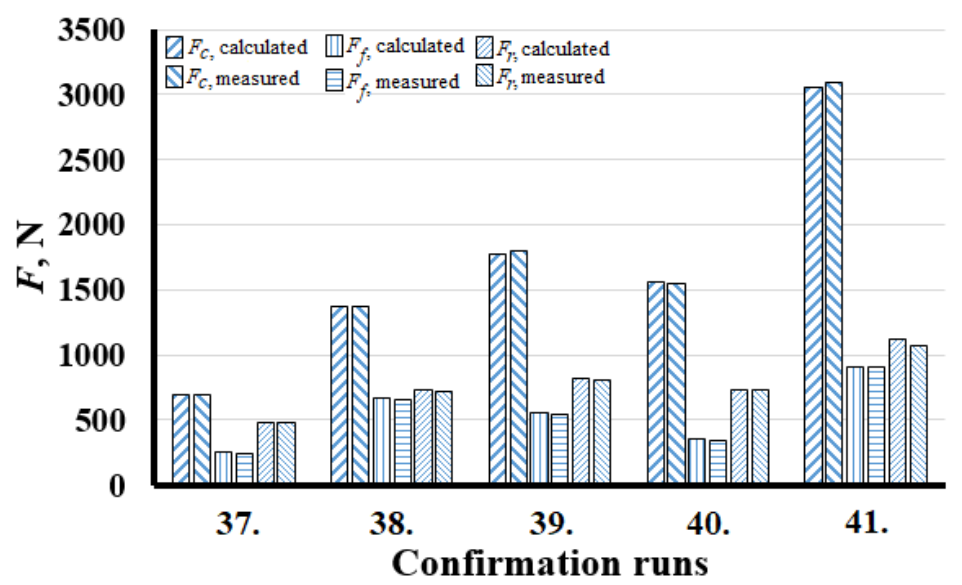

Figure 15. Results of the confirmation measurements.

\section{Discussion}

Within the framework of the research presented above, a Kienzle principle [6,7] based new force model was introduced for turning with round insert that was extended with a new approach with the help of the equivalency of the chip cross-section. The model presented above can be included in and enhance the classical types of cutting force models using mechanical analogy (cutting force/chip cross-section). The model can be used in technological process planning and for further studies of the generated cutting forces in the case of similar tool geometries. The theoretical background and applicability were demonstrated through a comprehensive case study providing promising results for accuracy and conformity. The ways of further development of the introduced force model can be studied from various aspects as follows. The empirical constants in the phenomenological model are mostly dependent on material (hardness and tensile strength of the workpiece material) and further parameters of the tool geometry. It might be useful to generalize them to material categories (see ISO DIN 513 and 3323 VDI, six classes of workpiece material), on which the model can be applied with adequate accuracy. In addition, further studies might reveal more detailed effects resulting from the cutting tool geometry. Furthermore, the application of force models based on the concept of the equivalent chip cross-section can be used in different technologies providing similar cross-section, such as ball end milling [55] or orthogonal turn-milling [56]. Moreover, investigating the detailed mechanistic approach of the chip formation in the case of round tool geometry and also the application of advanced finite element analysis can be another vital research area [57]. 


\section{Conclusions}

In this paper, a new force model was created for cutting with round insert. In that case, the geometry of the undeformed chip cross-section strongly differs from the conventional one. Therefore, $h_{e q}$ and $l_{e f f}$ parameters were introduced that are characterizing the cut chip cross-section of round insert. Based on the investigations, the following conclusions can be drawn:

- It was demonstrated that the specific cutting force components $\left(k_{c}, k_{f}, k_{r}\right)$ could be determined in the form of Equation (23) in a wide range of technological parameters with adequate accuracy;

- It was stated that increasing $h_{e q}$ results in higher values of specific cutting forces for each direction;

- The changes of $l_{e f f}$ values have a non-significant effect on $k_{c}$, but for $k_{f}$ and $k_{r}$ have. The increased level of $l_{\text {eff }}$ gives a higher value for $k_{f}$ but a lower one for $k_{r}$;

- The residuals of the generated specific force models were examined on normality plots. It was concluded that the residuals follow a normal distribution with a mean of approximately zero. In addition, the standard deviation of the relative deviations is a low value. As a result, the accuracy of the models is proper for technological process planning;

- The accuracy of the created force models handling the special geometric features of the undeformed chip cross-section of round insert is high enough for each component $\left(F_{c}\right.$, $\left.F_{f}, F_{r}\right)$ in a wide range of technological parameters from roughing to fine technologies. The deviations in the directions are: for main cutting force $\left(F_{c}\right)-3.79 \% \ldots+4.43 \%$, for feed force component $\left(F_{f}\right)-5.4 \% \ldots+5.99 \%$, and for radial force component $\left(F_{r}\right)$ $-4.49 \% \ldots+4.77 \%$;

- The introduced force model can be easily applied for further material types after preliminarily determining the empirical constant by a few properly selected experimental runs. Thus, the process planning procedure can be improved;

- The strengths of the model include that the introduced model operates with easily calculable parameters. However, it can be said that the empirical constants in the phenomenological models are mostly material dependent (tensile strength-hardness) from the workpiece side; which might prognose further studies.

Author Contributions: Conceptualization, J.L. and R.H.; methodology, J.L. and R.H.; software, R.H.; validation, J.L. and R.H.; formal analysis, J.L.; investigation, R.H.; resources, R.H.; writing—original draft preparation, J.L. and R.H.; writing-review and editing, J.L.; visualization, R.H.; supervision, J.L.; All authors have read and agreed to the published version of the manuscript.

Funding: This research received no external funding.

Institutional Review Board Statement: Not applicable.

Informed Consent Statement: Not applicable.

Data Availability Statement: The all measured andused data are available in this study.

Conflicts of Interest: The authors declare no conflict of interest. The funders had no role in the design of the study; in the collection, analyses, or interpretation of data; in the writing of the manuscript, or in the decision to publish the results. 


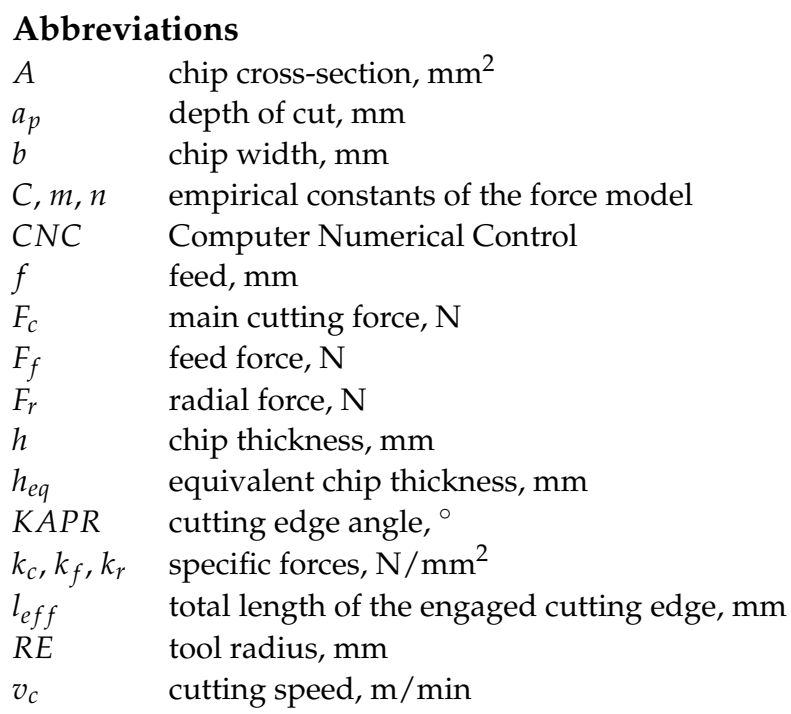

\section{References}

1. Polini, W.; Carrino, L.; Giorleo, G.; Prisco, U. Dimensional errors in longitudinal turning based on the unified generalized mechanics of cutting approach. Part II: Mechining process analysis and dimensional error estimate. Int. J. Mach. Tools Manuf. 2002, 42, 1517-1525.

2. Smith, G.T. Cutting Tool Technology: Industrial Handbook; Springer Science \& Business Media: Berlin/Heidelberg, Germany, 2008.

3. Gonzalo, O.; Seara, J.M.; Guruceta, E.; Izpizua, A.; Esparta, M.; Zamakona, I.; Uterga, N.; Aranburu, A.; Thoelen, J. A method to minimize the workpiece deformation using a concept of intelligent fixture. Robot. Comput.-Integr. Manuf. 2017, 48, 209-218. [CrossRef]

4. Outeiro, J.; Dias, A.; Lebrun, J.; Astakhov, V. Machining residual stresses in AISI 316L steel and their correlation with the cutting parameters. Mach. Sci. Technol. 2002, 6, 251-270. [CrossRef]

5. Germain, D.; Fromentin, G.; Poulachon, G.; Bissey-Breton, S. From large-scale to micromachining: A review of force prediction models. J. Manuf. Process. 2013, 15, 389-401. [CrossRef]

6. Kienzle, O. Die bestimmung von kräften und Leistungen an spanenden Werkzeugen und Werkzeugmaschinen. VDI-Z 1952, 94, 299-305.

7. Kienzle, O.; Victor, H. Spezifische schnittkräfte bei der metallbearbeitung. Werkstattstech. Maschinenbau 1957, 47, $224-225$.

8. Bali, J. Forgácsolás (Cutting). In University Textbook (in Hungarian); Tankönyvkiadó: Budapest, Hungary, 1988.

9. Debongnie, J.F. Cours de Methodes de Fabrication; AEES: Liège, Belgium, 2010.

10. Illés, D. Gépgyártástechnológia II. (Manufacturing technology II.). In Forgácsoláselmélet, (Cutting Theory) University Textbook (in Hungarian); Miskolci Egyetemi Kiadó: Miskolc, Hungary, 2001.

11. König, W. Fertigungsverfahren 1: Drehen, Fräsen, Bohren; Springer: Berlin/Heidelberg, Germany, 2008.

12. Tönshoff, H.K. Spanen: Grundlagen; Springer: Berlin/Heidelberg, Germany, 2013.

13. Korkut, I.; Boy, M. Experimental examination of main cutting force and surface roughness depending on cutting parameters. Stroj. Vestn. 2008, 54, 531-538.

14. Günay, M.; Korkut, I.; Aslan, E.; Şeker, U. Experimental investigation of the effect of cutting tool rake angle on main cutting force. J. Mater. Process. Technol. 2005, 166, 44-49. [CrossRef]

15. Saglam, H.; Yaldiz, S.; Unsacar, F. The effect of tool geometry and cutting speed on main cutting force and tool tip temperature. Mater. Des. 2007, 28, 101-111. [CrossRef]

16. Velchev, S.; Kolev, I.; Ivanov, K. Research on the influence of the cutting speed on the specific cutting force during turning. Stroj. Vestn. 2009, 55, 400-405.

17. Fernández-Abia, A.I.; Barreiro, J.; de Lacalle, L.N.L.; Martínez-Pellitero, S. Behavior of austenitic stainless steels at high speed turning using specific force coefficients. Int. J. Adv. Manuf. Technol. 2012, 62, 505-515. [CrossRef]

18. Aouici, H.; Bouchelaghem, H.; Yallese, M.; Elbah, M.; Fnides, B. Machinability investigation in hard turning of AISI D3 cold work steel with ceramic tool using response surface methodology. Int. J. Adv. Manuf. Technol. 2014, 73, 1775-1788. [CrossRef]

19. Ahearne, E.; Baron, S. Fundamental mechanisms in orthogonal cutting of medical grade cobalt chromium alloy (ASTM F75). CIRP J. Manuf. Sci. Technol. 2017, 19, 1-6. [CrossRef]

20. Biró, I.; Szalay, T. Extension of empirical specific cutting force model for the process of fine chip-removing milling. Int. J. Adv. Manuf. Technol. 2017, 88, 2735-2743. [CrossRef]

21. Guo, Y.; Duflou, J.R.; Qian, J.; Tang, H.; Lauwers, B. An operation-mode based simulation approach to enhance the energy conservation of machine tools. J. Clean. Prod. 2015, 101, 348-359. [CrossRef] 
22. Tapoglou, N.; Mehnen, J.; Butans, J.; Morar, N.I. Online on-board optimization of cutting parameter for energy efficient CNC milling. Procedia CIRP 2016, 40, 384-389. [CrossRef]

23. Gonçalves, D.A.; Schroeter, R.B. Modeling and simulation of the geometry and forces associated with the helical broaching process. Int. J. Adv. Manuf. Technol. 2016, 83, 205-215. [CrossRef]

24. Nikolaos, T.; Aristomenis, A. CAD-based calculation of cutting force components in gear hobbing. J. Manuf. Sci. Eng. 2012, 134, 031009. [CrossRef]

25. Tapoglou, N.; Mammas, A.; Antoniadis, A. Influence of machining data on developed cutting forces in gear hobbing. Int. J. Mach. Mach. Mater. 2013, 14, 66-76. [CrossRef]

26. Antoniadis, A.; Vidakis, N.; Bilalis, N. A simulation model of gear skiving. J. Mater. Process. Technol. 2004, 146, 213-220. [CrossRef]

27. Antoniadis, A. Gear skiving-CAD simulation approach. Comput.-Aided Des. 2012, 44, 611-616. [CrossRef]

28. Kyratsis, P.; Bilalis, N.; Antoniadis, A. CAD-based simulations and design of experiments for determining thrust force in drilling operations. Comput.-Aided Des. 2011, 43, 1879-1890. [CrossRef]

29. Kyratsis, P.; Tapoglou, N.; Bilalis, N.; Antoniadis, A. Thrust force prediction of twist drill tools using a 3D CAD system application programming interface. Int. J. Mach. Mach. Mater. 2011, 10, 18-33. [CrossRef]

30. Tapoglou, N.; Antoniadis, A. 3-Dimensional kinematics simulation of face milling. Measurement 2012, 45, 1396-1405. [CrossRef]

31. De Oliveira, F.B.; Rodrigues, A.R.; Coelho, R.T.; De Souza, A.F. Size effect and minimum chip thickness in micromilling. Int. J. Mach. Tools Manuf. 2015, 89, 39-54. [CrossRef]

32. Zhang, T.; Liu, Z.; Xu, C. Theoretical modeling and experimental validation of specific cutting force for micro end milling. Int. J. Adv. Manuf. Technol. 2015, 77, 1433-1441. [CrossRef]

33. Anand, R.S.; Patra, K.; Steiner, M. Size effects in micro drilling of carbon fiber reinforced plastic composite. Prod. Eng. 2014, 8, 301-307. [CrossRef]

34. Maier, T.; Zaeh, M.F. Modeling of the thermomechanical process effects on machine tool structures. Procedia CIRP 2012, 4, 73-78. [CrossRef]

35. Ntziantzias, I.; Kechaglas, J.; Fountas, N.; Maropoulos, S.; Vaxevanidis, N.M. A cutting force model in turning of glass fiber reinforced polymer composite. In Proceedings of the International Conference on Economic Engineering and Manufacturing Systems, Brasov, Romania, 24-25 November 2011; pp. 348-351.

36. Hertel, M.; Dix, M.; Putz, M. Analytic model of process forces for orthogonal turn-milling. Prod. Eng. 2018, 12, 491-500. [CrossRef]

37. Weng, J.; Zhuang, K.; Zhu, D.; Guo, S.; Ding, H. An analytical model for the prediction of force distribution of round insert considering edge effect and size effect. Int. J. Mech. Sci. 2018, 138, 86-98. [CrossRef]

38. Zhuang, K.; Weng, J.; Zhu, D.; Ding, H. Analytical modeling and experimental validation of cutting forces considering edge effects and size effects with round chamfered ceramic tools. J. Manuf. Sci. Eng. 2018, 140, 081012. [CrossRef]

39. Horváth, R. A New Model for Fine Turning Forces. Acta Polytech. Hung. 2015, 12, 109-128.

40. Horváth, R.; Pálinkás, T.; Mátyási, G.; Drégelyi-Kiss, Á.G. The design, calibration and adaption of a dynamometer for fine turning. Int. J. Mach. Mach. Mater. 2017, 19, 1-16. [CrossRef]

41. Horváth, R.; Lukács, J. Application of a Force Model Adapted for the Precise Turning of Various Metallic Materials. Stroj. Vestn./J. Mech. Eng. 2017, 63, 489-500. [CrossRef]

42. Ribeiro Filho, S.L.M.; Pereira, R.B.D.; Lauro, C.H.; Brandão, L.C. Investigation and modelling of the cutting forces in turning process of the Ti-6Al-4V and Ti-6Al-7Nb titanium alloys. Int. J. Adv. Manuf. Technol. 2019, 101, 2191-2203. [CrossRef]

43. Baro, P.K.; Joshi, S.S.; Kapoor, S. Modeling of cutting forces in a face-milling operation with self-propelled round insert milling cutter. Int. J. Mach. Tools Manuf. 2005, 45, 831-839. [CrossRef]

44. Ghorbani, H.; Moetakef-Imani, B. Specific cutting force and cutting condition interaction modeling for round insert face milling operation. Int. J. Adv. Manuf. Technol. 2016, 84, 1705-1715. [CrossRef]

45. Weng, J.; Zhuang, K.; Chen, D.; Guo, S.; Ding, H. An analytical force prediction model for turning operation by round insert considering edge effect. Int. J. Mech. Sci. 2017, 128, 168-180. [CrossRef]

46. Nieslony, P.; Krolczyk, G.; Chudy, R.; Wojciechowski, S.; Maruda, R.; Biłous, P.; Lipowczyk, M.; Stachowiak, L. Study on physical and technological effects of precise turning with self-propelled rotary tool. Precis. Eng. 2020, 66, 62-75. [CrossRef]

47. Smith, G.T. Application Guide: Railway Turning, (Re-Turning and New Wheel Turning); Sandvik Coromant: Sandviken, Sweden, 2018.

48. Bus, C.; Touwen, N.; Veenstra, P.; Van Der Wolf, A. On the significance of equivalent chip thickness. Ann. CIRP 1971, 19, 121-124.

49. Aouici, H.; Yallese, M.A.; Chaoui, K.; Mabrouki, T.; Rigal, J.F. Analysis of surface roughness and cutting force components in hard turning with CBN tool: Prediction model and cutting conditions optimization. Measurement 2012, 45, 344-353. [CrossRef]

50. El Hakim, M.; Shalaby, M.; Veldhuis, S.; Dosbaeva, G. Effect of secondary hardening on cutting forces, cutting temperature, and tool wear in hard turning of high alloy tool steels. Measurement 2015, 65, 233-238.

51. Fetecau, C.; Stan, F. Study of cutting force and surface roughness in the turning of polytetrafluoroethylene composites with a polycrystalline diamond tool. Measurement 2012, 45, 1367-1379. [CrossRef]

52. Gokkaya, H.; Taskesen, A. The effects of cutting speed and feed rate on BUE-BUL formation, cutting forces and surface roughness when machining Aa6351 (T6) alloy. Stroj. Vestn. 2008, 7, 521-530. 
53. Meddour, I.; Yallese, M.; Khattabi, R.; Elbah, M.; Boulanouar, L. Investigation and modeling of cutting forces and surface roughness when hard turning of AISI 52100 steel with mixed ceramic tool: Cutting conditions optimization. Int. J. Adv. Manuf. Technol. 2015, 77, 1387-1399. [CrossRef]

54. Nayak, M.; Sehgal, R. Effect of tool material properties and cutting conditions on machinability of AISI D6 steel during hard turning. Arab. J. Sci. Eng. 2015, 40, 1151-1164. [CrossRef]

55. Wojciechowski, S. The estimation of cutting forces and specific force coefficients during finishing ball end milling of inclined surfaces. Int. J. Mach. Tools Manuf. 2015, 89, 110-123. [CrossRef]

56. Qiu, W.; Liu, Q.; Yuan, S. Modeling of cutting forces in orthogonal turn-milling with round insert cutters. Int. J. Adv. Manuf. Technol. 2015, 78, 1211-1222. [CrossRef]

57. Davim, J.P. Mechanical and Industrial Engineering: Historical Aspects and Future Directions; Springer: Berlin/Heidelberg, Germany, 2021. 